NASZA DERMATOLOGIA Online OUR DERMATOLOGY Online

Source of Support: Nil

Competing Interests: None

\section{DISTAL NAIL EMBBEDING}

\author{
Patricia Chang ${ }^{1}$, Monica Vanesa Vásquez Acajabón ${ }^{2}$
}

\author{
${ }^{l}$ Department of Dermatology, Hospital General de Enfermedades IGSS and Hospital \\ Ángeles, Guatemala \\ ${ }^{2}$ Hospital General de Enfermedades IGSS and Hospital Ángeles, Guatemala
}

Corresponding author: Patricia Chang, MD PhD

pchang2622@gmail.com
Male patient, 35 years old who came to dermatological consultation due to contact dermatitis on back, during his clinical examination alterations of his digits was seen.

Dermatological examination reveals a rim of tissue at the distal edge of the nail of both big toenails and thickened nails (Fig.1a - c, 2a, b). Both big toenails were removed due to ingrown nails two times.

Diagnosis of distal nail embedding was done.

Distal nail embedding is a rim of tissue at the distal edge of the nail. Causes can de acquired or congenital. Although the main cause of distal embedding is total nail avulsion, there are more causes, such as: pincer nails, bad alignment of nail [1], or detachment of the nail caused by a subungual hematoma $[1,2]$. The hyponychium is the tissue located beneath the free edge of the nail [1]. In the distal nail embedding, the nail plate is blocked by the hyponychium, which cause a distal ring that obstructs the normal nail to grow [3]. Loss of counter-pressure induced by the disappearance of the nail plate allows dorsal expansion of the distal pulp. It promotes distal embedding $[2,4]$ with a subsequent hyperkeratotic reaction facing the impaction of the nail, producing pain and inflammation $[1,4]$.

The distal nail embedding may occur during Infancy. In this case the nail presents a distal edge of tissue and hypertrophy of its lateral edge. This prominent edge of tissue forms an anterior wall that allows the embedding and avoids the normal growing of the free margin of the nail. This congenital deformity may worsen by factors like sleeping in prone. If the nail is aligned normally, the good growth of the nail may reestablish at the age of 6 months [5]. Distal nail embedding may be associated to different causes such as onychomycosis (Fig. 3a - f), bad cut polish (Fig. 4a - c), onychodystrophy (Fig. 5a - e) use steel tip shoe (Fig. 6).

If the patient is asymptomatic or complains of minor discomfort, conservative treatment is indicated: reducing the hyperkeratotic process in front of the distal nail, using 50\% urea ointment and debridement with scalpel. Massaging back in a distal-plantar direction is recommended. If there is severe pain, then surgery is mandatory to free the distal edge of the nail plate using the Dubois' procedure resection of a part of the distal wall, from and to each proximal end of the lateral nail fold $[2,4]$.

When possible, partial nail avulsion should always be preferred. If the nail is avulsed for matrix or nail bed surgery, the nail plate should be put back in place and sutured to the lateral nail fold. If the nail is shed afterwards, the patient should be instructed to keep it in place using adhesive tape as long as possible [4].

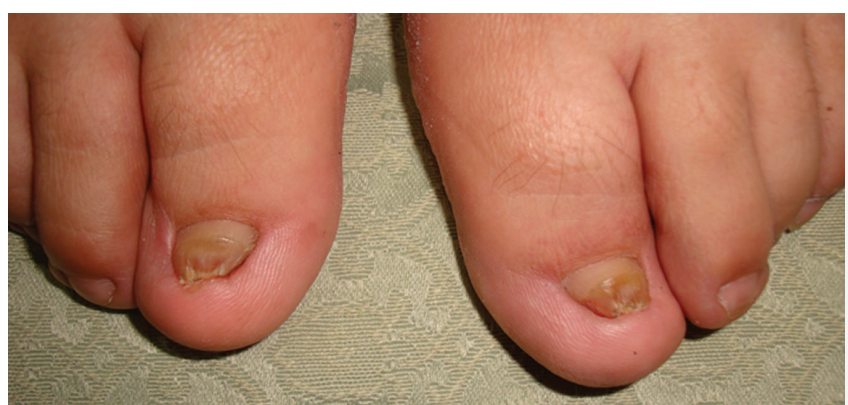

Figure 1a. Panoramic view of distal nail embedding of both toenail.

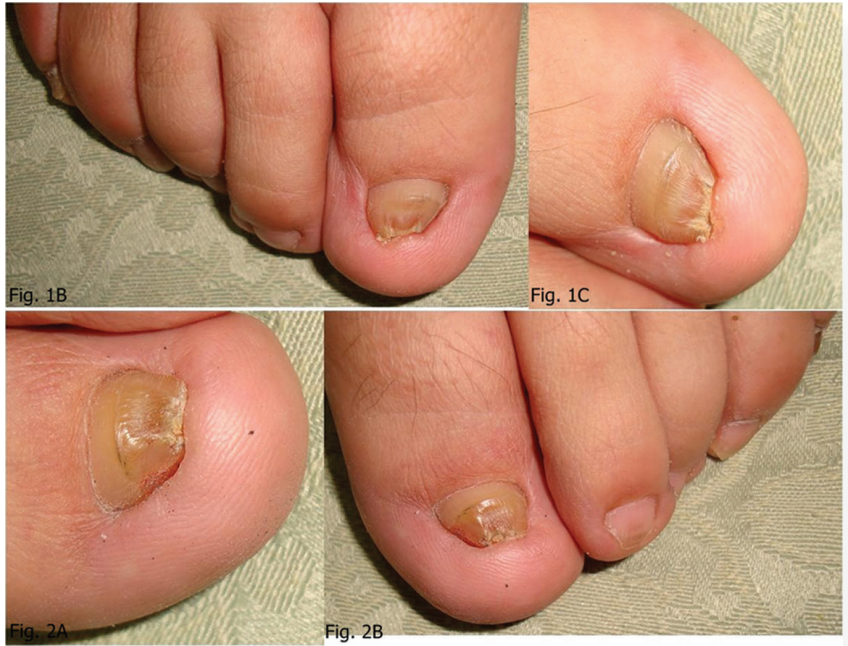

Figure 1 Panoramic view of distal nail embedding of both toenail. Right and left distal nail embedding. 


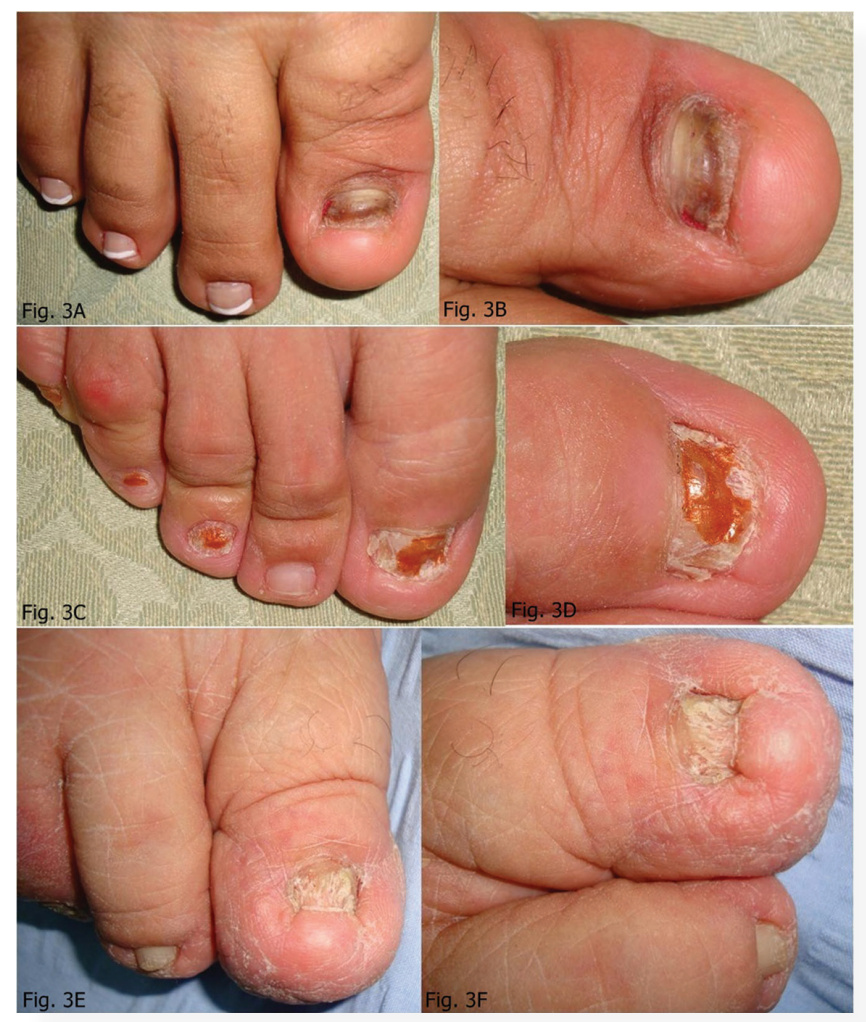

Figure 3 a-f. Distal nail embedding short nail due to onychomycosis.
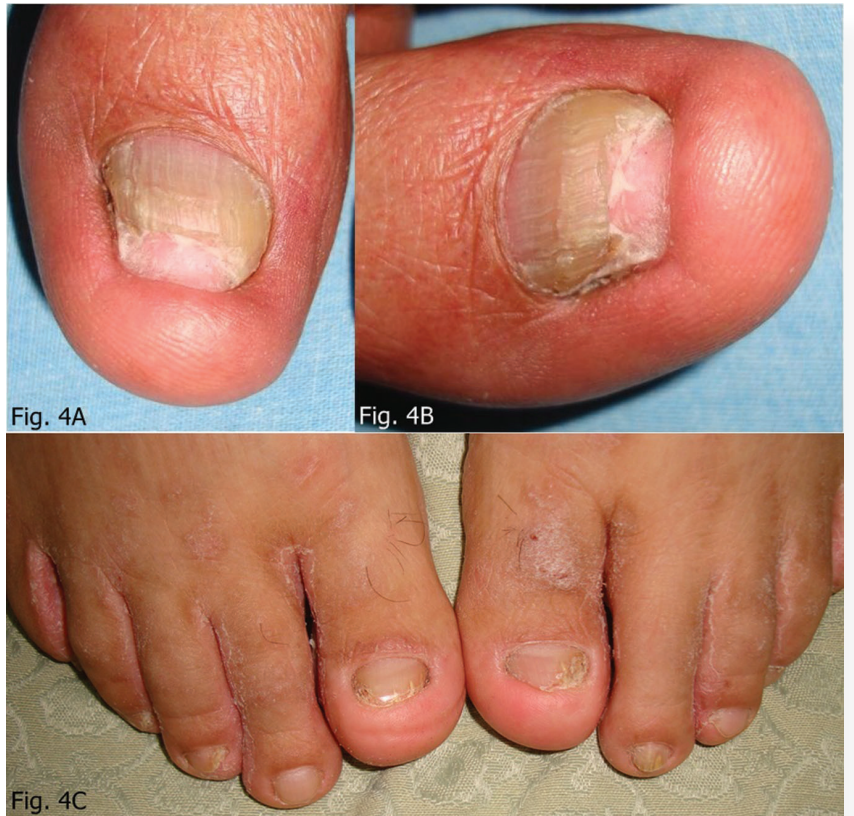

Figure 4 a-c. Distal nail embedding due to bad cut polish.

\section{REFERENCES}

1. Chang P, Rodas C. Encajamiento ungueal distal. Reporte de 24 casos. Dermatología CMQ. 2011;9:91-5.

2. Baran R, Dawber RP, Haneke E, Tosti A, Bristow IA. Text Atlas of nail disorders Techniques in investigation and diagnosis. Marin Dunitz, London and New York, 2003:250-2.

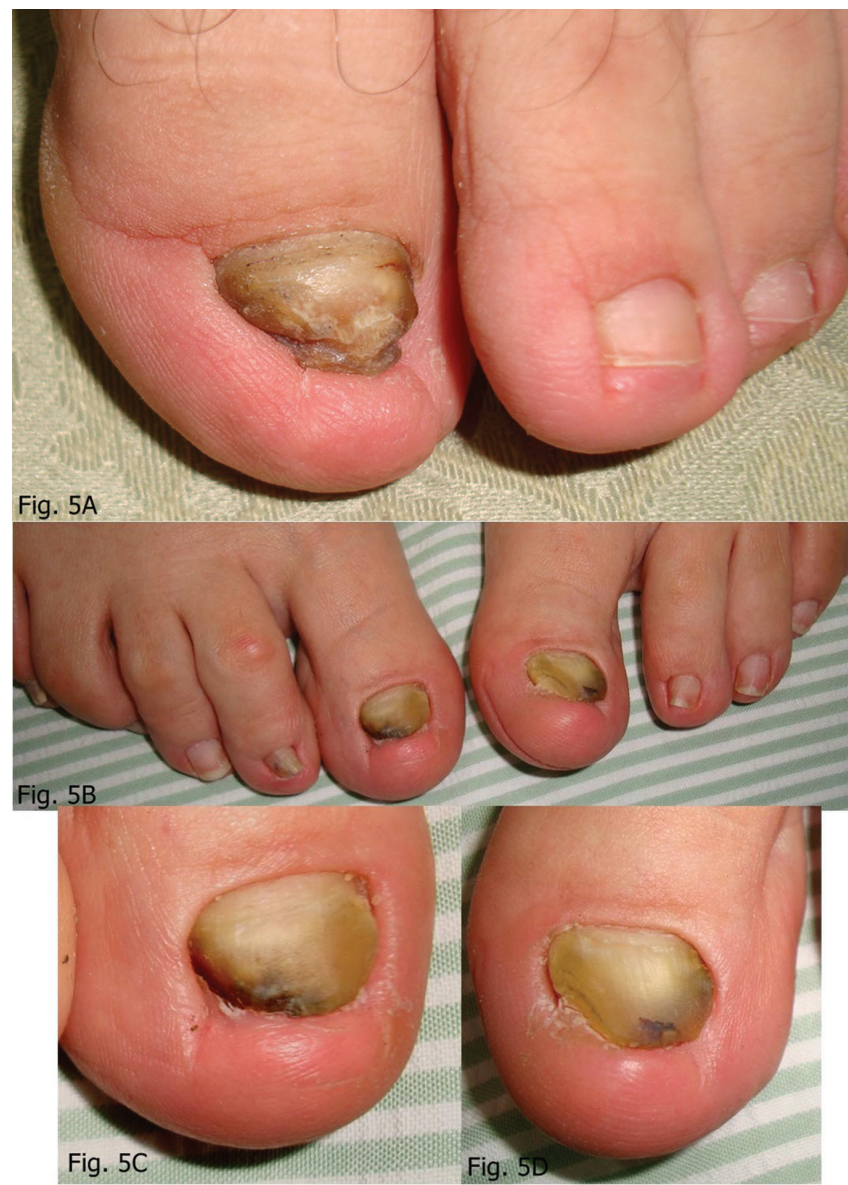

Figure 5 a-d. Distal nail embedding due to onychodystrophy.

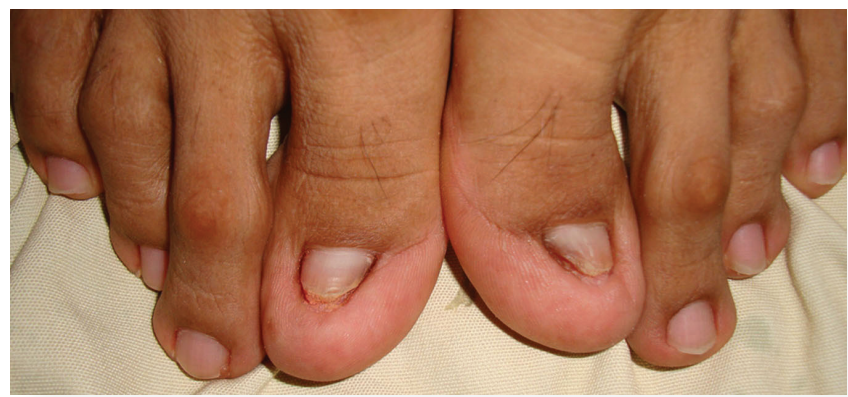

Figure 6. Distal nail embedding due to steel tip shoe.

3. Bolognia JL, Rapini RP. Dermatology. Mosby Elsevier, Philadelphia, 2008:1032.

4. Nouri K. Complications in Dermatologic Surgery Saunders Elsevier. Philadelphia. 2008:147.

5. Baran R, Dawber RP, Berker D, Haneke E, Tosti A. Diseases o the nails and their management. Blackwell, Oxford. 2011:120-3.

Copyright by Patricia Chang, et al. This is an open access article distributed under the terms of the Creative Commons Attribution License, which permits unrestricted use, distribution, and reproduction in any medium, provided the original author and source are credited. 